\title{
Differential prescribing of opioid analgesics according to physician specialty for Medicaid patients with chronic noncancer pain diagnoses
}

\author{
Chris Ringwalt DrPH ${ }^{1,2}$, Hallam Gugelmann MD MPH ${ }^{3}$, Mariana Garrettson $\mathrm{MPH}^{1}$, Nabarun Dasgupta $\mathrm{MPH} \mathrm{PhD}^{1,4}$,
} Arlene E Chung MD MHA MMCi ${ }^{5,6,7}$, Scott K Proescholdbell MPH ${ }^{8}$, Asheley Cockrell Skinner PhD ${ }^{5,9}$

\begin{abstract}
C Ringwalt, H Gugelmann, M Garrettson, et al. Differential prescribing of opioid analgesics according to physician specialty for Medicaid patients with chronic noncancer pain diagnoses. Pain Res Manag 2014;19(4):179-185.
\end{abstract}

BACKGROUND: Despite $>20$ years of studies investigating the characteristics of patients seeking or receiving opioid analgesics, research characterizing factors associated with physicians' opioid prescribing practices has been inconclusive, and the role of practitioner specialty in opioid prescribing practices remains largely unknown.

OBJECTIVE: To examine the relationships between physicians' and other providers' primary specialties and their opioid prescribing practices among patients with chronic noncancer pain $(\mathrm{CNCP})$.

METHODS: Prescriptions for opioids filled by 81,459 Medicaid patients with CNCP in North Carolina (USA), 18 to 64 years of age, enrolled at any point during a one-year study period were examined. $\chi^{2}$ statistics were used to examine bivariate differences in prescribing practices according to specialty. For multivariable analyses, maximum-likelihood logistic regression models were used to examine the effect of specialty on prescribing practices, controlling for patients' pain diagnoses and demographic characteristics.

RESULTS: Of prescriptions filled by patients with CNCP, who constituted $6.4 \%$ of the total sample of 1.28 million individuals, $12.0 \%$ were for opioids. General practitioner/family medicine specialists and internists were least likely to prescribe opioids, and orthopedists were most likely. Across specialties, men were more likely to receive opioids than women, as were white individuals relative to other races/ethnicities. In multivariate analyses, all specialties except internal medicine had higher odds of prescribing an opioid than general practitioners: orthopedists, OR 7.1 (95\% CI 6.7 to 7.5 ); dentists, OR 3.5 (95\% CI 3.3 to 3.6); and emergency medicine physicians, OR 2.7 (95\% CI 2.6 to 2.8 ).

CONCLUSIONS: Significant differences in opioid prescribing practices across prescriber specialties may be reflective of differing norms concerning the appropriateness of opioids for the control of chronic pain. If so, sharing these norms across specialties may improve the care of patients with CNCP.

Key Words: Chronic noncancer pain; Medicaid; Medical specialties; Opioids; Prescribing patterns

$\mathrm{P}$ ain constitutes one of the most prevalent diagnoses in primary care settings (1), and is the complaint presented by nearly two-thirds of emergency department patients treated in the United States (US) (2). Estimates of the prevalence of all chronic pain in the US population range considerably, from $8 \%$ to $48 \%$, depending on the stringency of the definitions used. One recent review offered a weighted estimate of $22 \%$ (3); a somewhat more dated review provided an estimate of $15 \%$ (4). Opioid analgesics are the mainstay for pharmacological treatment for moderate to
La prescription différentielle d'analgésiques opioïdes en fonction de la spécialité des médecins aux patients sur Medicaid atteints de douleurs non cancéreuses chroniques diagnostiquées

HISTORIQUE : Même si pendant plus de 20 ans, des études ont porté sur les caractéristiques des patients demandant ou recevant des analgésiques opioïdes, les données caractérisant les facteurs associés aux pratiques de prescription d'opioïdes par les médecins ne sont pas concluantes, et on ne sait pas grandchose du rôle de la spécialité du praticien dans les pratiques de prescription. OBJECTIF : Examiner la relation entre les principales spécialités des médecins et des autres dispensateurs et leurs pratiques de prescription d'opioïdes auprès des patients atteints de douleurs non cancéreuses chroniques (DNCC).

MÉTHODOLOGIE : Les chercheurs ont examiné les prescriptions d'opioïdes remplies par 81459 patients souffrant de DNCC de 18 à 64 ans sur Medicaid habitant en Caroline du Nord (États-Unis), inscrits à un moment ou à un autre pendant une étude d'un an. Ils ont examiné les statistiques $\chi^{2}$ pour examiner les différences bivariées des pratiques de prescription en fonction de la spécialité. Dans les analyses multivariables, ils ont utilisé les modèles de régression logistique à pertinence maximale pour examiner l'effet de la spécialité sur les pratiques de prescription, le contrôle des diagnostics de douleur des patients et les caractéristiques démographiques.

RÉSULTATS : Parmi les prescriptions remplies par les patients ayant des DNCC, qui représentaient 6,4 \% de l'échantillon total de 1,28 million de personnes, 12,0 \% l'étaient pour des opioïdes. Les omnipraticiens ou spécialistes en médecine familiale et les internes étaient les moins susceptibles de prescrire des opioïdes, et les orthopédistes l'étaient le moins. Au sein des spécialités, les hommes étaient plus susceptibles de recevoir des opioïdes que les femmes, et les personnes de race blanche davantage que celles des autres races ou ethnies. Dans les analyses multivariées, toutes les spécialités, sauf la médecine interne, étaient plus susceptibles de prescrire un opioïde que les praticiens généraux : orthopédistes, RC 7,1 (95\% IC 6,7 à 7,5); dentistes, RC 3,5 (95 \% IC 3,3 à 3,6); et médecins d'urgence, RC 2,7 (95\% IC 2,6 à 2,8). CONCLUSIONS : Les différences significatives des pratiques de prescription d'opioïdes en fonction des spécialités des prescripteurs reflètent peut-être des normes différentes quant à la pertinence des opioïdes pour contrôler la douleur chronique. Dans l'affirmative, il serait bon de partager ces normes dans toutes les spécialités pour améliorer les soins aux patients ayant des DNCC.

severe pain and have improved the quality of life for many (5-7). However, in the first decade of the 21st century, the amount of prescription analgesics, such as fentanyl, hydrocodone, methadone, oxymorphone and oxycodone, increased by a factor of four (8), and deaths due to the abuse and misuse of such analgesics nearly doubled (9). In 2009, poisoning deaths became the leading cause of injury-related death in the US (10).

The recent advent of the Food and Drug Administration's Risk Evaluation and Mitigation Strategies for extended-release and

${ }^{1}$ Injury Prevention Research Center, University of North Carolina at Chapel Hill; ${ }^{2}$ Pacific Institute for Research and Evaluation, Chapel Hill,

North Carolina; ${ }^{3}$ Department of Emergency Medicine, Perelman School of Medicine, University of Pennsylvania, Philadelphia, Pennsylvania;

${ }^{4}$ Department of Epidemiology, Gillings School of Global Public Health; ${ }^{5}$ Division of General Pediatrics Eु Adolescent Medicine, Department of

Pediatrics, School of Medicine; ${ }^{6}$ Division of General Medicine 83 Clinical Epidemiology, Department of Medicine, School of Medicine; ${ }^{7}$ Cecil G Sheps Center for Health Services Research, University of North Carolina at Chapel Hill, Chapel Hill; ${ }^{8}$ North Carolina Division of Public

Health, Chronic Disease and Injury Section, Raleigh; ${ }^{9}$ Department of Health Policy and Management, Gillings School of Global Public Health,

University of North Carolina at Chapel Hill, Chapel Hill, North Carolina, USA

Correspondence: Dr Asheley Cockrell Skinner, University of North Carolina at Chapel Hill School of Medicine, 231 MacNider Building, 229B,

CB 7225, Chapel Hill, North Carolina 27599, USA. Telephone 919-843-9941, fax 919-966-5945, e-mail asheley@unc.edu 
long-acting opioid analgesics attempts to introduce consistency into prescribing behaviours (6) and to reduce the potential for harm among patients at risk for addiction or misuse. However, the Risk Evaluation and Mitigation Strategies provide little guidance regarding conditions, doses and opioid medication types because the regulation of medical practice is left to the states and cannot be regulated by the Food and Drug Administration. The American Society of Interventional Pain Physicians, the American Pain Society and the National Opioid Use Guideline Group of Canada have all developed guidelines to assist physicians in the management of opioids in chronic noncancer pain (CNCP); however, these serve as process management strategies rather than specific prescribing guidelines (11-13). The definition of what constitutes 'adequate' pain treatment remains unclear, and no particular treatment regimen has been endorsed by any single medical organization (14-16).

Despite more than two decades' worth of studies of the characteristics of patients seeking or receiving opioid analgesics, research characterizing factors associated with physicians' opioid prescribing practices has been inconclusive. For example, while some investigations have linked such prescriptions to pain scores $(17)$, others have not $(18,19)$, and have suggested instead that patients' pain-related behaviours particularly the level of distress and disability they manifest - may be more closely associated with prescribing practices than their scores.

The role of practitioner specialty in opioid prescribing practices remains largely unknown, with conflicting results across studies $(14,20)$. A recent study involving two million enrollees in a national health care plan revealed that specialists were more likely than nonspecialists $(19.1 \%$ versus $13.7 \%)$ to prescribe an extended-release opioid for episodes of pain lasting at least 60 days (7). In contrast, a study involving almost 7000 physicians found that rheumatologists and general practitioners were more likely to prescribe long-term opioids than surgeons, neurologists and psychiatrists (21). In a nationally representative sample of 121 million patients that included prescription data from more than one-half of the nation's retail pharmacies, Volkow et al (22) reported that primary care physicians (ie, general practitioners [GPs], and family medicine providers [FMs] and primary care internists) were the most likely providers $(28.8 \%)$ to prescribe opioids, relative to internists $(14.6 \%)$, dentists $(8.0 \%)$ and orthopedic surgeons $(7.7 \%)$. Furthermore, a study involving physicians who faced criminal prosecution or charges by medical boards for inappropriate opioid prescribing practices between 1998 and 2006 found that 39\% were either general practitioners or family physicians, relative to $4 \%$ who were either self-identified or board certified as pain specialists (23). The lack of conclusive research in this area has led one set of investigators to conclude that opioid prescribing practices are idiosyncratic and based largely on providers' personal beliefs regarding their appropriateness (24). It appears to be reasonable to suspect that these beliefs may cluster according to specialty due, in part, to the varying patient populations served by each.

In the present study, we examined the relationship between physicians' primary specialties and their opioid prescribing practices among patients with CNCP. Given the preponderant findings of the scant and conflicting evidence presented above, we expected to find that nonspecialists - eg, GPs - would be more likely than specialists to prescribe opioid analgesics to this population.

\section{METHODS}

\section{Data}

Adults eligible for the Medicaid program in North Carolina (USA) include individuals whose incomes are below a defined threshold and who also receive cash assistance programs, are blind or disabled, or satisfy other need-based criteria (25). North Carolina Medicaid claims data for the 12-month period from October 1, 2009 to September 30, 2010 were examined. The dataset was limited to adults $<65$ years of age because many of the claims for those $\geq 65$ years of age may have been filed with the Medicare program and their Medicaid records were, thus, unlikely to provide a complete history of their diagnoses and related prescriptions. The dataset comprised 1.28 million individuals 18 to 64 years of age in all types of Medicaid program categories including income-based and disability-based categories. In the total population, $30.5 \%$ were men. With regard to race/ethnicity, $47.4 \%$ were white, $36.6 \%$ black, $8.5 \%$ Hispanic and $7.4 \%$ other; $43.5 \%$ were 18 to 30 years of age, $23.4 \%$ were 31 to 40 years of age, $15.9 \%$ were 41 to 50 years of age, and $17.3 \%$ were 51 to 64 years of age.

Study data were obtained from the Cecil G Sheps Center for Health Services Research of the University of North Carolina (Chapel Hill, North Carolina, USA), which in turn received them from the Division of Medical Assistance of the North Carolina Department of Health and Human Services. The present study was approved by the University of North Carolina Institutional Review Board for the Protection of Human Subjects.

\section{Measures}

Medicaid patients were identified as having CNCP if they had an International Classification of Diseases - Ninth Revision diagnosis code at any point during the 12 -month study period for: chronic pain syndrome, headaches (migraine, tension or chronic), back pain, neck pain, spinal cord injury, arthritic diseases (including lupus and fibromyalgia), sickle cell anemia and burns. Patients were excluded from analysis if they had both a cancer and a chronic pain diagnosis.

Opioid analgesics were defined as a prescription for a drug in therapeutic class code 40, based on the 1995 National Drug Code directory of therapeutic drug classes (26). For the purpose of the present study, CNCP patients were only specified as receiving an opioid analgesic if they filled the prescription either on the same day or the day following the date of physician diagnosis in their medical record. This strategy was used to increase the likelihood that the opioid prescription prescribed would be related to the diagnosis.

Specialties that were believed to be likely to prescribe a majority of opioids were examined. Physicians reported their specialties to Medicaid, which were subsequently categorized as: ear, nose and throat (ENT); dentists; GP/FMs; internal medicine; emergency medicine; orthopedics; obstetrics and gynecology $(\mathrm{OB} / \mathrm{GYN})$; or other. No specialties were excluded; any physicians who did not endorse any of these specialties were included in the 'other' category. Physicians had the opportunity to specify up to three different specialties in their Medicaid provider files, although, in practice, $<5 \%$ of the providers identified more than one of the specialties listed. The following rules were used for classifying physicians according to specialty. Physicians were considered to be ENTs, dentists, emergency medicine, orthopedics or OB/GYNs if they included the specialty in any of the three specialties they specified. Physicians were considered to be internists or GPs if they indicated only that specialty code because medicine subspecialties also have internal medicine board certification; thus, those practicing as primary care physicians could also be included. For example, a physician categorized as both an internist and a cardiologist was included in the 'other' category, not the internal medicine category.

\section{Statistical analysis}

First, the dataset was examined to determine the potential impact of missing data related to provider specialty on the study results. As will be observed in the following section, it was concluded that any bias introduced by these missing data was likely to be modest and, thus, missing data were not considered further.

$\chi^{2}$ statistics were used to examine bivariate differences in prescribing practices according to specialty. For multivariable analyses, maximum-likelihood logistic regression models were used to examine the effect of specialty on prescribing practices, controlling for patients' demographic characteristics and specific diagnoses. The SEs for within-person similarities across multiple prescriptions (eg, an individual is likely to receive care from the same specialist) were adjusted using a sandwich variance estimator. SEs were calculated using the Huber-White robust variance method (27), after subtracting the number of covariates from the number of observations. Sandwich variance estimators, which are used with generalized estimating equations, 
TABLE 1

Characteristics of Medicaid patients, 18 to 64 years of age, with a diagnosis of chronic noncancer pain, according to filled opioid prescription

\begin{tabular}{|c|c|c|c|}
\hline Characteristic & Any opioid prescription filled $(n=51,793)$ & No opioid prescription filled $(n=29,666)$ & Total $(n=81,459)$ \\
\hline Total & 63.58 & 36.42 & \\
\hline \multicolumn{4}{|l|}{ Sex } \\
\hline Male & 29.40 & 32.02 & 30.35 \\
\hline Female & 70.60 & 67.98 & 69.65 \\
\hline \multicolumn{4}{|l|}{ Race/ethnicity } \\
\hline White & 63.97 & 53.53 & 60.16 \\
\hline Black & 28.60 & 38.17 & 32.08 \\
\hline Hispanic/Latino & 1.63 & 2.36 & 1.90 \\
\hline Other & 5.81 & 5.94 & 5.86 \\
\hline \multicolumn{4}{|l|}{ Age, years } \\
\hline 18-30 & 26.14 & 24.38 & 25.50 \\
\hline $31-40$ & 25.41 & 19.32 & 23.20 \\
\hline $41-50$ & 24.19 & 24.13 & 24.16 \\
\hline $51-64$ & 24.26 & 32.17 & 27.14 \\
\hline \multicolumn{4}{|l|}{ Diagnosis* } \\
\hline Chronic pain syndrome & 44.44 & 30.02 & 39.19 \\
\hline Headache & 7.73 & 8.18 & 7.89 \\
\hline Back pain & 54.79 & 45.71 & 51.48 \\
\hline Neck pain & 24.89 & 22.44 & 24.00 \\
\hline Spinal cord injury & 1.29 & 3.88 & 2.23 \\
\hline Arthritic diseases & 2.75 & 4.67 & 3.45 \\
\hline Sickle cell anemia & 1.29 & 1.66 & 1.42 \\
\hline Burns & 0.15 & 0.23 & 0.18 \\
\hline
\end{tabular}

Data presented as \%. *The total exceeds $100 \%$ because patients may be given multiple pain-related diagnoses

TABLE 2

Proportion of all prescriptions and all opioid prescriptions filled for chronic noncancer pain patients 18 to 64 years of age, according to specialty for patients with provider specialty data

\begin{tabular}{|c|c|c|c|}
\hline Provider specialty & $\mathrm{n}(\%)$ of all prescriptions filled (column $\%)$ & $\begin{array}{l}\mathrm{n}(\%) \text { of all opioid prescriptions filled } \\
\text { (column } \% \text { ) }\end{array}$ & $\begin{array}{c}\text { Opioid prescriptions as \% of all } \\
\text { prescriptions filled, according to specialty } \\
\text { (row \%) }\end{array}$ \\
\hline ENT & $5186(0.40)$ & $560(0.36)$ & 10.80 \\
\hline Dentists & $28,194(2.17)$ & 7492 (4.78) & 26.57 \\
\hline GP/FM/DO & $405,786(31.16)$ & $35,881(22.89)$ & 8.84 \\
\hline Internal medicine & $262,846(20.19)$ & $22,188(14.16)$ & 8.44 \\
\hline Emergency medicine & $87,903(6.75)$ & $19,924(12.71)$ & 22.67 \\
\hline Orthopedists & $28,178(2.16)$ & $11,768(7.51)$ & 41.76 \\
\hline OB/GYN & $49,686(3.82)$ & $5032(3.21)$ & 10.13 \\
\hline Other specialty & $434,389(33.36)$ & $53,877(34.38)$ & 12.40 \\
\hline Total prescriptions & $1,302,168(100)$ & $156,722(100)$ & 12.04 \\
\hline
\end{tabular}

DO Doctor of osteopathic medicine; ENT Ear, nose and throat; GP General practitioner; FM Family medicine; OB/GYN Obstetrics and gynecology

provide reliable estimates of covariance matrices even in the absence of parametric models (28). All analyses were performed using Stata 12.0 (Stata Corp, USA).

\section{RESULTS}

Sample description

Data examined for the 12 -month period beginning in July 2009 included 1.28 million patients. Of these, 81,459 (6.4\%) had a diagnosis code for CNCP associated with visits from July 2009 through June 2010, and 215,463 (16.9\%) of the 1.28 million had filled a prescription for an opioid analgesic at least once during the year. Collectively, $51,793(4.1 \%)$ of all Medicaid patients between 18 and 64 years of age had received both a CNCP diagnosis and at least one prescription for an analgesic, either on the same day of or subsequent to the day their diagnosis was recorded.

As indicated in Table 1, among patients with CNCP diagnoses, the majority were female $(69.7 \%)$, white $(60.2 \%)$ and were approximately evenly distributed across the age groupings specified. Almost two-thirds $(63.6 \%)$ had filled at least one opioid prescription during the year. There were more white patients in the group that filled an opioid prescription $(64.0 \%)$ than in the group that did not $(53.5 \%)$. Although age was evenly distributed among patients who filled at least one opioid prescription, those who did not fill one were more likely to be older. Table 1, which also includes information about the distribution of key clusters of diagnoses related to chronic pain, reveals that patients with chronic pain syndrome and back pain, relative to the other pain-related diagnoses examined, were particularly likely to receive a prescription for an opioid.

Study findings

All analyses of prescribing according to specialty are based on the 73,487 (90.2\%) individuals with CNCP who filled at least one prescription of any type, regardless of whether it was an analgesic, on the day of or following the visit in which they received a CNCP diagnosis code. Of all prescriptions filled by individuals with CNCP, $12.5 \%$ were for opioids. Table 2 presents the distribution of 
TABLE 3

Percent of all prescriptions for chronic noncancer pain patients that were for opioids, according to provider specialty and patient demographics

\begin{tabular}{|c|c|c|c|c|c|c|c|c|c|c|}
\hline \multirow[b]{2}{*}{ Provider specialty } & \multicolumn{2}{|c|}{ Sex } & \multicolumn{4}{|c|}{ Race } & \multicolumn{4}{|c|}{ Age, years } \\
\hline & $\begin{array}{c}\text { Women } \\
(n=962,758)\end{array}$ & $\begin{array}{c}\text { Men } \\
(n=339,410)\end{array}$ & $\begin{array}{c}\text { White } \\
(n=880,090)\end{array}$ & $\begin{array}{c}\text { Black } \\
(n=323,302)\end{array}$ & $\begin{array}{c}\text { Hispanic } \\
(n=21,932)\end{array}$ & $\begin{array}{c}\text { Other } \\
(n=76,844)\end{array}$ & $\begin{array}{c}18-30 \\
(n=215,440)\end{array}$ & $\begin{array}{c}31-40 \\
(n=282,622)\end{array}$ & $\begin{array}{c}41-50 \\
(n=353,963)\end{array}$ & $\begin{array}{c}51-64 \\
(n=450,143)\end{array}$ \\
\hline ENT & 9.4 & 16.4 & 11.0 & 11.3 & 11.1 & 7.4 & 13.7 & 10.6 & 11.3 & 8.1 \\
\hline Dentists & 26.0 & 27.5 & 27.1 & 25.1 & 26.2 & 27.4 & 27.4 & 26.3 & 26.3 & 25.0 \\
\hline GP/FM/DO & 8.2 & 10.4 & 9.3 & 8.0 & 7.2 & 7.7 & 11.3 & 11.0 & 9.3 & 6.7 \\
\hline Internal medicine & 7.8 & 10.0 & 9.0 & 7.6 & 7.9 & 7.0 & 12.0 & 11.0 & 8.7 & 6.5 \\
\hline Emergency medicine & 21.9 & 24.9 & 23.2 & 22.1 & 19.7 & 18.8 & 25.2 & 25.0 & 21.9 & 16.9 \\
\hline Orthopedists & 40.8 & 44.0 & 42.4 & 39.4 & 43.2 & 45.7 & 40.6 & 42.5 & 44.1 & 39.1 \\
\hline OB/GYN & 9.7 & 21.2 & 11.0 & 7.9 & 9.3 & 8.4 & 9.3 & 10.8 & 12.3 & 8.9 \\
\hline Other & 11.5 & 14.9 & 12.8 & 11.4 & 10.0 & 12.4 & 12.1 & 13.9 & 12.5 & 11.3 \\
\hline
\end{tabular}

Data presented as \%. DO Doctor of osteopathic medicine; ENT Ear, nose and throat; GP General practitioner; FM Family medicine; OB/GYN Obstetrics and gynecology

\section{TABLE 4}

Percent of all prescriptions for chronic noncancer pain patients that were for opioids, according to provider specialty and chronic pain diagnosis

\begin{tabular}{|c|c|c|c|c|c|c|c|c|}
\hline Provider specialty & $\begin{array}{c}\text { Chronic pain } \\
(n=641,674)\end{array}$ & $\begin{array}{c}\text { Headache } \\
(n=103,869)\end{array}$ & $\begin{array}{l}\text { Back pain } \\
(n=676,360)\end{array}$ & $\begin{array}{l}\text { Neck pain } \\
(n=309,649)\end{array}$ & $\begin{array}{c}\text { Spinal cord } \\
\text { injury } \\
(n=29,279)\end{array}$ & $\begin{array}{c}\text { Arthritis } \\
\text { diseases } \\
(n=49,844)\end{array}$ & $\begin{array}{c}\text { Sickle cell } \\
\text { anemia } \\
(n=11,721)\end{array}$ & $\begin{array}{c}\text { Burns } \\
(n=2749)\end{array}$ \\
\hline ENT & 12.2 & 8.8 & 9.9 & 11.9 & 3.4 & 15.4 & 3.3 & 0.0 \\
\hline Dentists & 30.0 & 26.1 & 27.9 & 27.1 & 16.7 & 25.7 & 33.1 & 38.9 \\
\hline GP/FM/DO & 11.1 & 8.0 & 8.8 & 8.7 & 8.4 & 8.0 & 18.4 & 2.6 \\
\hline Internal medicine & 10.6 & 8.2 & 8.1 & 7.6 & 7.6 & 7.5 & 24.3 & 11.3 \\
\hline Emergency medicine & 25.0 & 21.6 & 24.6 & 25.3 & 10.1 & 20.5 & 45.4 & 11.9 \\
\hline Orthopedists & 42.2 & 44.0 & 44.7 & 46.8 & 33.0 & 44.2 & 46.0 & 54.8 \\
\hline OB/GYN & 14.9 & 9.1 & 10.4 & 9.3 & 7.7 & 8.9 & 13.3 & 4.8 \\
\hline Other & 15.0 & 8.7 & 14.4 & 13.6 & 10.3 & 10.0 & 24.7 & 9.2 \\
\hline
\end{tabular}

Data presented as \%. DO Doctor of osteopathic medicine; ENT Ear, nose and throat; GP General practitioner; FM Family medicine; OB/GYN Obstetrics and gynecology

specialties associated with all prescriptions $(n=1,302,168)$, as well as all opioid prescriptions $(\mathrm{n}=156,722)$, and also presents the proportion of the total number of prescriptions that each type of specialist wrote that represented an opioid prescription. Consistent with their greater representation in the population of providers, most dispensed prescriptions were written by GP/FMs and by internal medicine specialists. These two specialties also accounted for the majority of opioid prescriptions written. Dentists wrote more than twice the percentage of opioid prescriptions $(4.8 \%)$ as they did of all prescriptions $(2.2 \%)$; similarly, emergency medicine providers were overrepresented among all opioid prescriptions $(12.7 \%)$ relative to their representation among all prescriptions (6.8\%). Prescriptions from the approximately one-third of providers whose specialty was not represented in one of the categories specified accounted for almost one-third of all prescriptions filled. Proportions of opioid prescribing relative to all prescriptions differed according to specialty. Of all prescriptions written for patients with $\mathrm{CNCP}, 8.8 \%$ and $8.4 \%$ were written for opioids by GP/FMs and internal medicine physicians, respectively. In contrast, $26.6 \%$ of all prescriptions written by dentists, $22.7 \%$ written by emergency medicine physicians and $41.8 \%$ written by orthopedists were for opioids.

Table 3 presents differential rates of specialists' prescriptions of opioids to patients, disaggregated according to their demographic characteristics. For every specialty, a greater percentage of all the prescriptions dispensed to men than women were for opioids. A greater proportion of prescriptions dispensed to white individuals were for opioids compared with other races. For all specialties, fewer of the prescriptions dispensed to older individuals (51 to 64 years of age) were for opioids, although this difference was greatest for GPs, internists and emergency medicine physicians. Orthopedists were the most likely of any specialty to have patients who received opioids: $44.0 \%$ of orthopedists' prescriptions for men were for opioids, as were $40.1 \%$ of their prescriptions for women. The relationships among types of specialists and chronic pain diagnoses are presented in Table 4. As this table reveals, a greater proportion of prescriptions written by GP/FM and internal medicine physicians were for opioids when the patient had received a diagnosis of a chronic pain syndrome or sickle cell anemia. A greater proportion of prescriptions written by emergency medicine physicians were for opioids when the patient had a diagnosis of sickle cell anemia, but a lower proportion were written by these physicians when the patient had a spinal cord injury or burns.

The results of the multivariable analyses, which are presented in Table 5, confirm the results of the bivariate analyses presented above. In these analyses, demographic and diagnostic covariates were controlled for; the ORs presented compare each specialty with GP/FMs, who served as the referent category. All specialties except internal medicine had higher odds of prescribing an opioid than GP/FMs. The odds were largest among orthopedists (OR 7.1), dentists (OR 3.5) and emergency medicine physicians (OR 2.7). When all other variables were held constant, patients with a diagnosis of sickle cell anemia were most likely (OR 3.2) to be prescribed an opioid than a prescription for any other medication.

Missing data concerning physician specialty

Prescriber number is not a required field for prescription claim reimbursement in the North Carolina Medicaid program. Of 3,034,168 prescriptions for patients 18 to 64 years of age who were diagnosed with CNCP from October 2009 to September 2010, 1,732,427 (57.1\%) lacked prescriber identification (and, thus, specialty information). Because of the initial concern that these data may have biased the analysis of the relationships among provider specialty and opioid prescriptions in the sample of patients with CNCP diagnoses, whether the presence of providers' data was related to their patients' demographic characteristics and primary diagnoses was examined (Table 6). In addition, the relationships between specialty-missing status and both any prescriptions $(n=3,034,168)$ and any opioid prescriptions $(n=380,036)$ 
TABLE 5

Logistic regression of likelihood of opioid prescriptions according to provider specialty* $(n=1,302,168)$

\begin{tabular}{lcr}
\hline & OR (95\% CI) & P \\
\hline Specialties* & & \\
ENT & $1.248(1.073-1.451)$ & 0.004 \\
Dentists & $3.461(3.313-3.616)$ & $<0.001$ \\
Internal medicine & $0.965(0.925-1.008)$ & 0.107 \\
Emergency medicine & $2.715(2.612-2.822)$ & $<0.001$ \\
Orthopedics & $7.115(6.718-7.535)$ & $<0.001$ \\
OB/GYN & $1.116(1.047-1.189)$ & $<0.001$ \\
Other & $1.392(1.342-1.443)$ & $<0.001$ \\
Age & $0.985(0.984-0.987)$ & $<0.001$ \\
Male & $1.304(1.264-1.344)$ & $<0.001$ \\
Race/ethnicity ${ }^{\star}$ & & \\
Black & $0.915(0.887-0.945)$ & $<0.001$ \\
Hispanic & $0.879(0.797-0.970)$ & 0.010 \\
Other & $0.918(0.866-0.973)$ & 0.004 \\
Pain diagnosis & & \\
Chronic pain & $1.875(1.823-1.929)$ & $<0.001$ \\
Headache & $1.052(1.001-1.105)$ & 0.045 \\
Back pain & $1.467(1.426-1.510)$ & $<0.001$ \\
Neck pain & $1.226(1.189-1.263)$ & $<0.001$ \\
Spinal cord injury & $0.934(0.825-1.057)$ & 0.279 \\
Arthritic diseases & $1.197(1.109-1.291)$ & $<0.001$ \\
Sickle cell anemia & $3.163(2.791-3.585)$ & $<0.001$ \\
Burns & $0.975(0.679-1.401)$ & 0.893 \\
Constant & $0.096(0.091-0.103)$ & $<0.001$ \\
\hline Geneal praction & & \\
\hline
\end{tabular}

${ }^{*}$ General practitioners/family medicine specialists constitute the referent for all specialties; 'White race/ethnicity constitute the referent for all racial/ethnic categories. ENT Ear, nose and throat; OB/GYN Obstetrics and gynecology

were examined. Because all comparisons made in this very large dataset were statistically significant, a focus was placed on whether any observed differences were meaningful. As presented in the table, differences according to sex were small $(<2 \%)$. With regard to race/ethnicity, nonHispanic/Latino individuals were less likely than white or black individuals to have any prescriptions that were missing specialty data; these differences were attenuated for opioid prescriptions, in which white individuals, black individuals and Hispanic/Latino individuals were all within two percentage points of one another. However, a clear trajectory was apparent across age groups - younger patients were less likely to have missing provider specialty data than older patients - although the difference in the percent of these data between the youngest and highest age groups was greater for all prescriptions $(6.0 \%)$ than opioid prescriptions $(4.6 \%)$. Examining the relationship between the presence or absence of specialty information and patients' chronic pain-related diagnoses revealed similarly small differences with regard to whether data for this variable were missing.

Given the small magnitude of the differences in patients' demographic characteristics and chronic pain diagnoses, missing specialty data were not imputed. Because it could not be determined whether the data were missing at random - ie, it was not possible to be certain that missing values could be explained entirely with available data there was a concern that any imputation procedures would risk generating more bias than that caused by the missing data themselves. Multivariate analyses were limited to cases with no missing data because the use of a dummy variable for a missing specialty could have also generated bias, and there was adequate power to address the study's research questions even when excluding those observations.

\section{DISCUSSION}

When controlling for patients' age, sex and race/ethnicity, and category of chronic pain diagnosis, and when compared with GPs/FMs, we found
TABLE 6

Percent of prescriptions missing data pertaining to physician specialization according to characteristics of chronic noncancer pain patients 18 to 64 years of age, for all prescriptions and all opioid prescriptions filled

\begin{tabular}{lcc}
\hline & \multicolumn{2}{c}{ Specialty missing (\%) } \\
\cline { 2 - 3 } & $\begin{array}{c}\text { All prescriptions } \\
(\mathbf{n}=\mathbf{3 , 0 3 4 , 5 9 5 )}\end{array}$ & $\begin{array}{c}\text { All opioid prescriptions } \\
\text { (n=380,036) }\end{array}$ \\
\hline Sex & & \\
Male & 57.85 & 59.85 \\
Female & 56.82 & 58.26 \\
Race/ethnicity & & \\
White & 56.39 & 58.54 \\
Black & 57.93 & 58.01 \\
Hispanic/Latino & 52.62 & 56.64 \\
Other & 61.89 & 64.62 \\
Age, years & & \\
18-30 & 53.24 & 56.28 \\
31-40 & 55.95 & 58.47 \\
41-50 & 57.23 & 58.74 \\
51-64 & 59.25 & 60.77 \\
Diagnosis & & \\
Chronic pain syndrome & 58.48 & 60.00 \\
Headache & 57.61 & 60.33 \\
Back pain & 57.04 & 58.86 \\
Neck pain & 55.77 & 58.03 \\
Spinal cord injury & 55.59 & 56.10 \\
Arthritic diseases & 55.34 & 55.43 \\
Sickle cell anemia & 55.57 & 57.44 \\
Burns & 66.21 & 59.39 \\
Total & 57.09 & 58.76 \\
\hline
\end{tabular}

that the following specialists had the highest odds of prescribing any opioid to their CNCP patients: orthopedists (by a ratio of 7.1 to 1 ), dentists ( 3.5 to 1 ) and emergency medicine physicians ( 2.7 to 1 ). This finding was contrary to our hypothesis that specialists would be less likely than GP/FMs to prescribe opioid medications, although it was consistent with findings reported by Victor et al (7). However, we observed no difference in the proportions of prescriptions between GP/ FMs and primary care internal medicine physicians, and only very small differences between GP/FMs and both ENTs and OB/GYNs.

The explanation for each of these prescribing patterns is likely to differ, and none should be considered to be potentially aberrant in the absence of a full consideration of the context and environment in which each specialist practices. Orthopedists, dentists and emergency medicine specialists may be more likely than GP/FMs to encounter patients who present with acute pain that may exacerbate or be concurrent with underlying chronic pain conditions and, thus, to write a relatively high proportion of opioid prescriptions. Orthopedists may also see CNCP patients on a repeated basis and, thus, may be more likely to bear responsibility for multiple and long-term opioid prescribing, especially if they are 'fine tuning' their patients' medication. Internists are more likely to write prescriptions for a variety of medications than are dentists, who would appear to be more likely to prescribe opioids to the exclusion of other medications because of the nature of their patients' pain complaints.

Our examination of the demographic characteristics of Medicaid patients with CNCP who filled prescriptions yielded some surprising results. The proportion of women who filled prescriptions for either opioids or, indeed, any medication was similar to the proportion of women in the population studied. However, when we disaggregated these data according to providers' specialty and patients' age ranges, male patients received a greater proportion of prescriptions for opioids almost uniformly across specialties. This difference was particularly pronounced for ENT 
specialists and OB/GYNs. Notably, we also found that ENTs prescribed 1.8 times as many opioids to men as to women. It is possible that men may be more likely to experience chronic pain as a result of injuries associated with physical labour, experience pain that they (or their providers) perceive to be more severe or that they are more heavily involved in drug diversion. It is also possible that male smokers are receiving more opioids because of oral and neck cancers. Future studies should examine the relationship between the potential for differential pain severity ratings according to sex and providers' opioid prescribing patterns. We also note that, controlling for physicians' specialties and patients' age, sex and pain diagnosis, white individuals were more likely to be prescribed opioids than black individuals, Hispanic individuals, and individuals of other races. This finding supports the presence of a significant health disparity in opioid prescribing practices, concerning which there is now considerable literature (29-31).

Prescribing of opioids according to specialty for specific diagnoses revealed clear patterns. A greater proportion of the prescriptions written by primary care internists and GP/FM physicians for those living with chronic pain conditions were for opioids, likely indicating that these physicians are providing much of the care for these patients. The greater proportion of prescriptions for opioids written by emergency medicine and primary care physicians for patients with sickle cell anemia likely represents treatment for acute pain crises.

\section{Limitations}

We acknowledge several limitations to our study. First, our study targeted Medicaid patients, who are twice as likely as those in the general population to receive an opioid prescription, possibly because of their elevated risk for severe illness and injury. Indeed, in many states, a disability diagnosis constitutes a key criterion for eligibility for the program (32). The substantial amount of documentation required to establish this diagnosis may also attenuate any providers' concerns that their patients' complaints of chronic pain may be spurious (33). Second, to the extent that the time physicians are able to spend with Medicaid patients is constrained, they may lack the time to consult their state's prescription monitoring program concerning their patients' history of prescriptions for controlled substances. Third, our findings should be generalized only with caution because the context in which providers prescribe, and pharmacists fill, prescriptions for controlled substances in North Carolina may differ from that of other states. For example, there is considerable variation across the states in the provisions of, registration with and utilization of their respective prescription drug monitoring programs, all of which could affect prescribing practices (34). There is also variation in the states' Medicaid Lock-in Programs, which are designed to prevent 'doctor shopping' and other fraudulent activity among high-risk patients (35).

We are also aware of the problems caused by missing specialty information in our dataset, particularly the potential for bias if these

\section{REFERENCES}

1. Volkow ND, McLellan TA. Curtailing diversion and abuse of opioid analgesics without jeopardizing pain treatment.

JAMA 2011;305:1346-7.

2. Cordell WH, Keene KK, Giles BK, Jones JB, Jones JH, Brizendine EJ. The high prevalence of pain in emergency medical care. Am J Emerg Med 2002;20:165-9.

3. Andrew R, Derry S, Taylor RS, Straube S, Phillips CJ. The costs and consequences of adequately managed chronic non-cancer pain and chronic neuropathic pain. Pain Practice 2014;1:79-94.

4. Manchikanti L, Ailinani H, Koyyalagunta D, et al. A systematic review of randomized trials of long-term opioid management for chronic non-cancer pain. Pain Physician 2011;14:91-121.

5. Bhamb B, Brown D, Hariharan J, Anderson J, Balousek S, Fleming MF. Survey of select practice behaviors by primary care physicians on the use of opioids for chronic pain. Curr Med Res Opin 2006;22:1859-65.

6. Gudin J. Risk Evaluation and Mitigation Strategies (REMS) for extended-release and long-acting opioid analgesics: Considerations for palliative care practice. J Pain Palliat Care Pharmacother 2012;26:136-43. data were differentially associated either with physicians' specialty or with their opioid prescriptions. However, our examination of the differences indicates few concerns about bias based on the data available. Furthermore, our study relied exclusively on a very large database of objective administrative records, as opposed to surveys that rely on self-reported behaviours, which may be subject to recall and social desirability biases and are often based on limited samples with low response rates. That said, more than one-third of all opioid prescriptions filled by this sample of individuals who had received a diagnosis of chronic pain were written by specialists who identified themselves as 'other'. Nurse practitioners comprised the plurality (17.7\%) of prescribers in the 'other' category, and their specialization was routinely unavailable, followed by anesthesiologists (16.9\%) and surgeons (13.4\%). A more granular analysis of the 'other' category did not alter the conclusions in the present study; therefore, we did not report these results.

\section{CONCLUSIONS}

In the present study we found, contrary to expectations, that specialists - and, in particular, orthopedists - were more likely than generalists $(\mathrm{GPs} / \mathrm{FMs}$ ) to write prescriptions for Medicaid CNCP patients. That said, we strongly caution against any conclusions to the effect that orthopedists - or any other specialists - may be prescribing opioids at an inappropriately high rate because the diagnoses of the types of patients seen by each category of specialists, and the context in which each practices, vary widely. More needs to be known about each specialty's standards and norms concerning prescribing analgesics, and the care of patients with CNCP diagnoses may be improved if these are shared across specialties.

Clinicians are in the unenviable position of weighing their responsibility to provide patient-centred, compassionate care to their patients with $\mathrm{CNCP}$ against the risk of a variety of harms to their patients (36), including abuse, addiction, dependence and overdose $(16,37,38)$. In the absence of clear and unequivocal guidelines regarding what constitutes best practice in pain management for CNCP patients, physicians must continue to be given considerable latitude to do what they believe is best for their patients.

DISCLOSURES: Nabarun Dasgupta was a member of the Risk Safety Advisory Board (RSAB) reviewing postmarketing surveillance data for Exalgo (extended-release hydromophone) for Covidien until September 2012. The RSAB has since been disbanded. The authors have no other conflicts of interest to report.

ACKNOWLEDGEMENTS: The Injury Prevention Research Center at UNC provided pilot funding for this project. Dr Skinner is supported by a NIH BIRWCH (K12 HD001441). Additional support came from CTSA grant to UNC-Chapel Hill (UL1RR025747).

7. Victor TW, Alvarez NA, Gould E. Opioid prescribing practices in chronic pain management: Guidelines do not sufficiently influence clinical practice. J Pain 2009;10:1051-7.

8. Prescription Painkiller Overdoses in the US. November, 2011. <www.cdc.gov/vitalsigns/PainkillerOverdoses/> (Accessed July 7, 2012).

9. Johnston BD. Harm reduction for unintentional poisoning. Inj Prev 2010;16:217-8

10. Paulozzi L, Dellinger A, Degutis L. Lessons from the past. Inj Prev 2012;18:70.

11. Chou R, Fanciullo GJ, Fine PG, et al. Clinical guidelines for the use of chronic opioid therapy in chronic noncancer pain. J Pain 2009;10:113-30.

12. Trescot AM, Boswell MV, Atluri SL, et al. Opioid guidelines in the management of chronic non-cancer pain. Pain Physician 2006;9:1-39.

13. Furlan AD, Reardon R, Weppler C. Opioids for chronic noncancer pain: A new Canadian practice guideline. CMAJ 2010;182:923-30.

14. Heins A, Homel P, Safdar B, Todd K. Physician race/ethnicity predicts successful emergency department analgesia. J Pain 2010;11:692-7. 
15. Hutchinson K, Moreland AM, de CWAC, Weinman J, Horne R. Exploring beliefs and practice of opioid prescribing for persistent non-cancer pain by general practitioners. Eur J Pain 2007;11:93-8.

16. Nwokeji ED, Rascati KL, Brown CM, Eisenberg A. Influences of attitudes on family physicians' willingness to prescribe long-acting opioid analgesics for patients with chronic nonmalignant pain. Clin Ther 2007;(29 Suppl):2589-602.

17. Fanciullo GJ, Ball PA, Girault G, Rose RJ, Hanscom B, Weinstein JN. An observational study on the prevalence and pattern of opioid use in 25,479 patients with spine and radicular pain. Spine (Phila Pa 1976) 2002;27:201-5.

18. Breckenridge J, Clark JD. Patient characteristics associated with opioid versus nonsteroidal anti-inflammatory drug management of chronic low back pain. J Pain 2003;4:344-50.

19. Turk DC, Okifuji A. What factors affect physicians' decisions to prescribe opioids for chronic noncancer pain patients? Clin J Pain 1997; 13:330-6.

20. Heins A, Grammas M, Heins JK, Costello MW, Huang K, Mishra S. Determinants of variation in analgesic and opioid prescribing practice in an emergency department. J Opioid Manag 2006;2:335-40.

21. Turk DC, Brody MC, Okifuji EA. Physicians' attitudes and practices regarding the long-term prescribing of opioids for non-cancer pain. Pain 1994;59:201-8.

22. Volkow ND, McLellan TA, Cotto JH, Karithanom M, Weiss SR. Characteristics of opioid prescriptions in 2009. JAMA 2011;305:1299-301.

23. Goldenbaum DM, Christopher M, Gallagher RM, et al. Physicians charged with opioid analgesic-prescribing offenses. Pain Med 2008;9:737-47.

24. Tamayo-Sarver JH, Dawson NV, Cydulka RK, Wigton RS, Baker DW. Variability in emergency physician decision making about prescribing opioid analgesics. Ann Emerg Med 2004;43:483-93.

25. Medicaid Eligibility Chart. 2013. < www.ncdhhs.gov/dma/medicaid/ medicaideligchart.pdf $>$ (Accessed August 14, 2013).

26. National Drug Code Directory. 2012. <www.fda.gov/drugs/ informationondrugs/ucm142438.htm> (Accessed November 29, 2012).
27. Maas CJ, Hox JJ. Robustness issues in multilevel regression analysis. Statistica Neerlandica 2004;58:127-37.

28. Kauermann G, Carroll RJ. The sandwich variance estimator: Efficiency properties and coverage probability of confidence intervals. Sonderforschungsbereich 386, Discussion Paper 189. 2000.

29. Anderson KO, Green CR, Payne R. Racial and ethnic disparities in pain: Causes and consequences of unequal care. J Pain 2009;10:1187-204.

30. Green CR. Disparities in pain management and palliative care. In: Handbook of Pain and Palliative Care. New York: Springer, 2012:795-808

31. Green CR, Anderson KO, Baker TA, et al. The unequal burden of pain: Confronting racial and ethnic disparities in pain. Pain Med 2003;4:277-94.

32. Olsen Y, Daumit GL, Ford DE. Opioid prescriptions by U.S. primary care physicians from 1992 to 2001. J Pain 2006;7:225-35.

33. Bendtsen P, Hensing G, Ebeling C, Schedin A. What are the qualities of dilemmas experienced when prescribing opioids in general practice? Pain 1999;82:89-96.

34. Prescription Drug Abuse, Addiction, and Diversion: Overview of State Legislative and Policy Initiatives. 2013. <www.iowa.gov/odcp/ docs/Rx\%20Mon\%20Programs\%20NAMSDL\%20March\%202013. pdf $>$ (Accessed August 14, 2013).

35. Center for Medicare and Medicaid Services. Drug Diversion in the Medicaid Program: State Strategies for Reducing Prescription Drug Diversion in Medicaid. In: Services DoHaH, ed. August 2011.

36. McLellan AT, Turner B. Prescription opioids, overdose deaths, and physician responsibility. JAMA 2008;300:2672-3.

37. Wolfert MZ, Gilson AM, Dahl JL, Cleary JF. Opioid analgesics for pain control: Wisconsin physicians' knowledge, beliefs, attitudes, and prescribing practices. Pain Med 2010;11:425-34.

38. Potter M, Schafer S, Gonzalez-Mendez E, et al. Opioids for chronic nonmalignant pain. Attitudes and practices of primary care physicians in the UCSF/Stanford Collaborative Research Network. University of California, San Francisco. J Fam Pract 2001;50:145-51. 


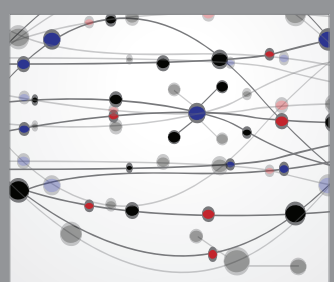

The Scientific World Journal
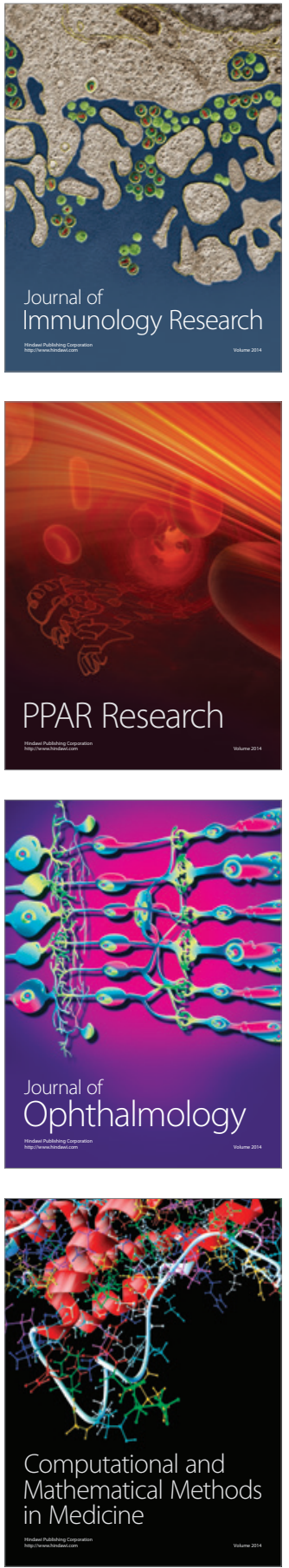

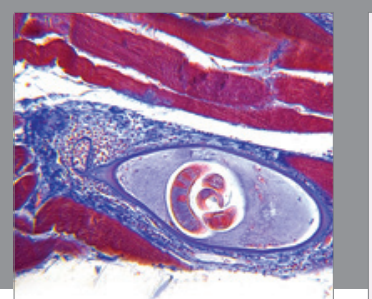

Gastroenterology Research and Practice

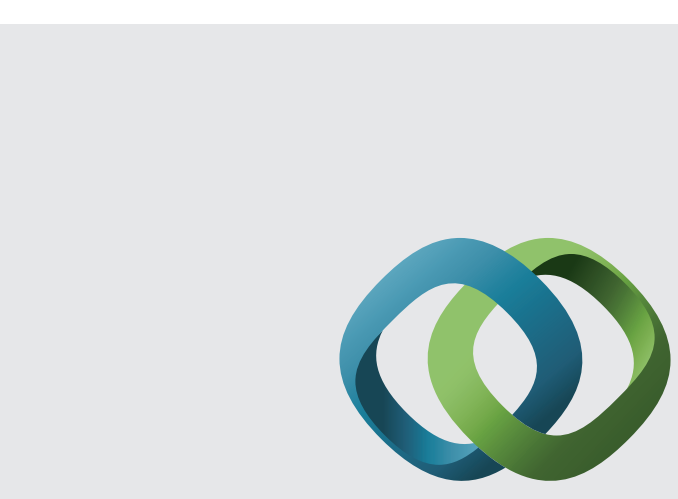

\section{Hindawi}

Submit your manuscripts at

http://www.hindawi.com
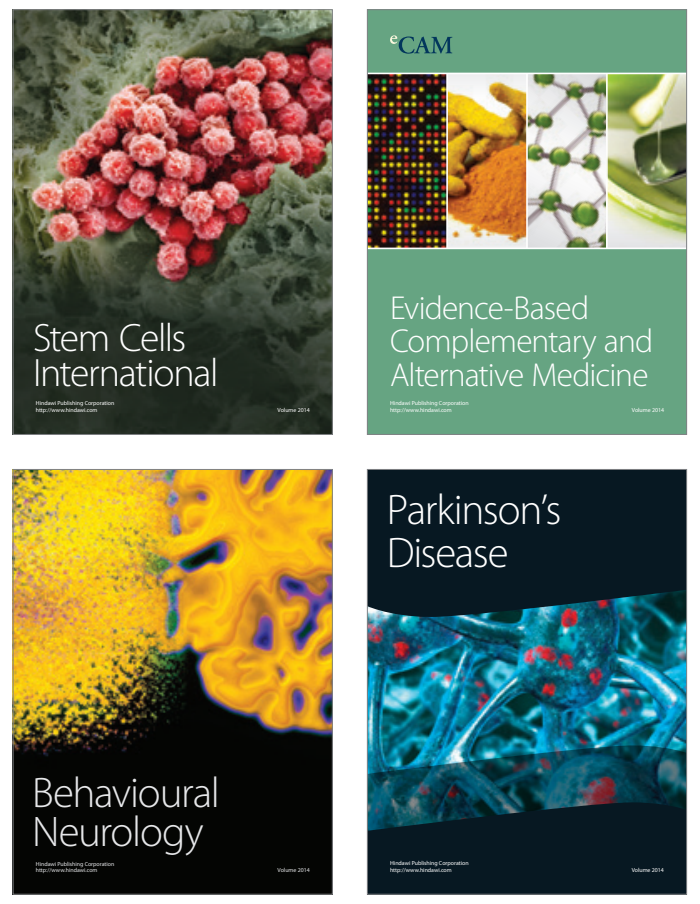
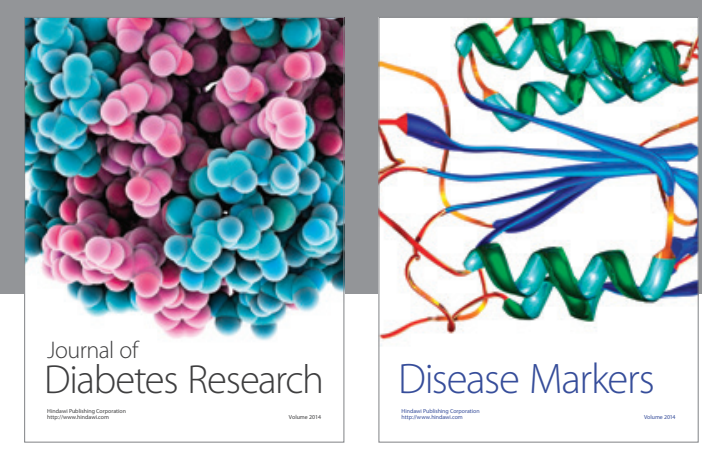

Disease Markers
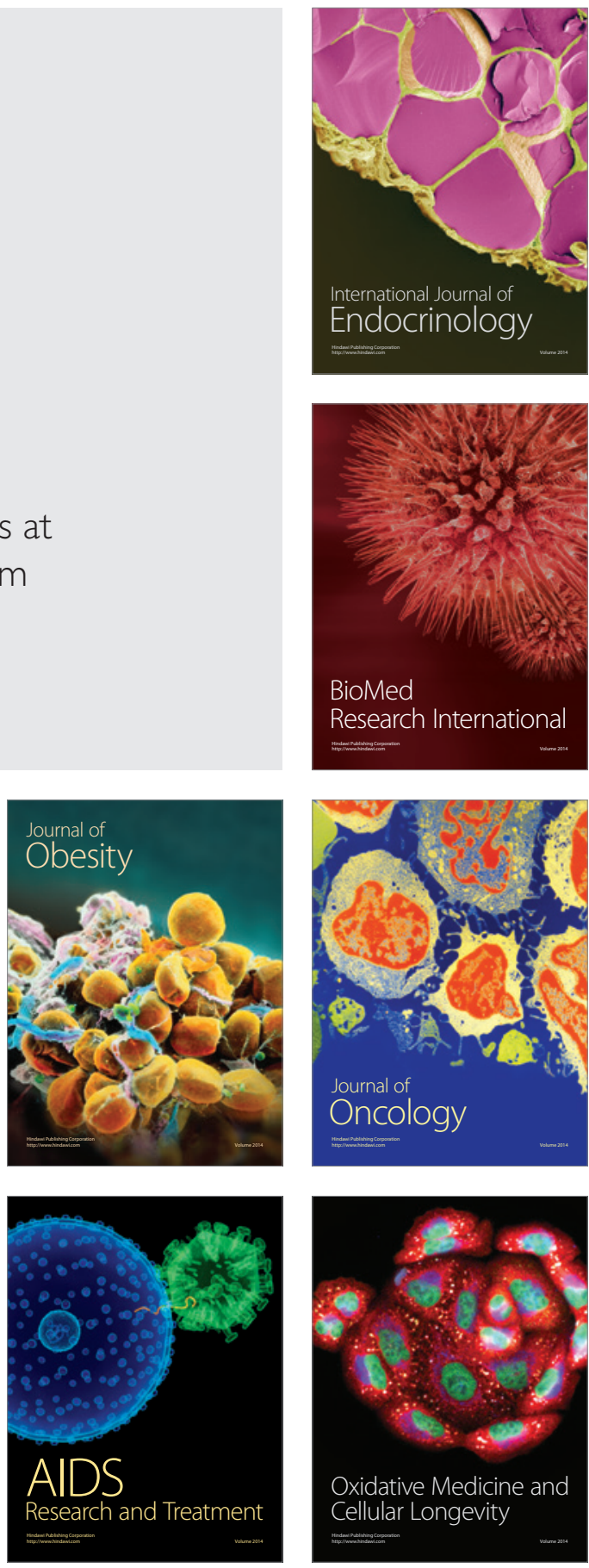